\title{
Investigations of sand-water induced erosive wear of AISI 304L stainless steel pipes by pilot-scale and laboratory-scale testing
}

\section{R.J.K. Wood*}

Surface Engineering and Tribology Group, School of Engineering Sciences, University of Southampton, Highfield, Southampton, SO17 1BJ, UK

* Corresponding author: Telephone: +44 (0) 2380594881 Fax: +44 (0) 238059 3230, Email: rjw3@ soton.ac.uk (R.J.K. Wood)

\section{T.F.Jones}

School of Chemical, Environmental and Mining Engineering, University of Nottingham, University Park, Nottingham, NG7 2RD, UK

\begin{abstract}
The repair costs of erosion damage caused by solid particle impingement from transporting slurries and other particle-laden liquids in pipes can be extremely high. In the absence of accurate predictive models, routine monitoring of the pipe wall thickness or the use of sacrificial coupons are required to warn of erosion damage or impending loss of containment. Apart from advantages for plant maintenance, the environmental, safety and production implications are enormous. Identification of critical pipe components susceptible to high levels of damage, and innovative ways to ameliorate the damage, has been an active topic of research for decades. Recent work at Nottingham and Southampton Universities [1] has sought definitions of flow fields and particle dispersions and their relationship to erosive wear to facilitate the development of new designs and geometries for slurry handling equipment.
\end{abstract}

This paper covers research that has been aimed at determining the distribution of erosion rates and the erosion mechanisms that occur over wetted surfaces within pilotscale pipe systems handling water-sand mixtures at $10 \%$ by volume concentrations and at a mean fluid velocity of approximately $3 \mathrm{~m} / \mathrm{s}$. Experiments are presented which have been conducted on a test section consisting of an upstream straight pipe 
section followed by a bend (with a radius of curvature of 1.2 bore diameters) within a $78 \mathrm{~mm}$ diameter pipe test loop. The whole loop and test section was manufactured from AISI 304L stainless steel. The wall wear rates, obtained by gravimetric measurements, as a function of time are discussed. Circumferential erosion penetration and mechanisms at discrete locations have been measured by surface profilometry on replicas and scanning electron microscopy after cutting-up the pipe sections. The erosion rates and patterns are compared to those predicted by erosion models linked to computational models for the impact velocity and impact angle in bend and straight sections. Bend wear patterns are further compared to flow visualisation results from a transparent flow loop and electrical resistance tomography (ERT) to confirm the placement of particle burdens. The erosion rates, expressed as volume loss per impact (determined gravimetrically and via computer models) in bends are found to agree well with simple laboratory scale water-sand jet impingement tests on planar stainless steel samples. The pipe loss data alone represents a significant resource for future erosion researchers to reference.

\section{Keywords: CFD, erosion, pipes, modelling}

\section{Introduction}

Efficient transportation of particle-bearing fluids and slurries is essential to many key industrial processes. An unfortunate consequence is damage from particle impingement, particularly at bends. Accurate prediction of this consequence is not possible for a number of reasons not least the probabilistic nature of the impacts themselves and the inhomogeneous nature of the pipe surfaces. Routine monitoring of pipe walls or the implantation and regular inspection of sacrificial coupons can be used to schedule replacements or maintenance, but the identification of the sections most at risk is still difficult.

The propensity to wear of bends and straights has been studied in a collaboration between the University of Nottingham and the University of Southampton $[1,3,4]$. This paper concerns the rates and mechanisms of erosion for specific pipe geometries. Pilot-scale pipe loop tests using sand and water mixtures, laboratory-scale sample 
testing and modelling had to be brought to bear on the problem. The laboratory work included free water-sand jet impingement tests on planar stainless steel samples. Typical pipeline transport flow velocities have been studied which generate asymmetric solid dispersions.

Vital to the modelling effort was the calculation of the position of particles in the pipe. Although not available for sand/water, Electrical Resistance Tomography (ERT), and flow visualisation results were available for $2 \mathrm{~mm}$ beads in a straight pipe of $50 \mathrm{~mm}$ bore.

\section{Slurry erosion modelling}

Slurry erosion is a complex and under-researched area and robust models have yet to be developed. This is certainly true for erosion of pipelines and the problem is compounded by the fact that most published literature on the wear of pipe work relates to pneumatic conveying systems. Meng [5] quotes 33 independent parameters in a recent review of 22 erosion models and predictive equations found in the literature.

Bends are an important part of most practical pipe configurations. Understanding the particle trajectories through bends is of great importance if wear rates are to be predicted at specific locations. Blanchard [6] attempted a two-dimensional model of particle trajectories in liquid flows within bends but with limited success due to the inability of the model to predict secondary flows. Forder [7] has studied solid particle trajectories in liquid flows in pipe bend geometry before modelling more complex flows in choke valves using a commercial CFD code. He extended a commercial CFD programme to include a predictive erosion element based on a combined deformation and cutting erosion model. The model was tested by comparing the predicted wear rates and wear locations in pipe bends with the experimental air/sand erosion results of Bourgoyne [8], with excellent correlations. Further experimental wear results for pipe bends could be used to test this approach in the future such as reported by King [9] and Wiedenroth [10] for a limited range of bend geometries, materials and solid-liquid flows. Xianghui Chen [11] has included a stochastic rebound model in a similar approach to Forder to investigate the modeling of erosion in elbows and plugged tees. The stochastic rebound model was found to 
have little effect on the predicted erosion of elbows subjected sand-water mixtures while differences were seen in the plugged tee geometry exposed to air-sand flows. However, Wiedenroth found the erosion rate to be proportional to $V^{2.4}$, where $V$ is the mean particle velocity taken as being equal to the flow velocity, for pipework downstream from an elbow in a $125 \mathrm{~mm}$ diameter steel pipework system tested at 8.2 $\mathrm{m} / \mathrm{s}$ with $30 \%$ concentration of $990 \mu \mathrm{m}$ diameter sand. This confirms that erosion models based on a particle velocity raised to a power of approximately 2.5 are applicable to pipe geometries. Symbols and their definitions may be found in Section 6.

The redistribution of solids inside horizontal bends for multisized particulate slurries has been experimentally studied by Ahmed [12]. Conclusions from this work point to the redistribution of large particles outwards to the likely cause of rapid bend erosion. A simple approach to erosion modelling might involve a single function to characterise erosion over the wide range of particle sizes and velocities encountered in industry. However, this would ignore parameters such as corrosion rate, squeeze film damping, Clark [13], centrifugal particle redistribution, particle rebound, asymmetry of flow patterns and particle fragmentation/degradation on impact.

Both the straight section and bend geometry were gridded into a Computational Fluid Dynamics (CFD) model. The data used for the erosion prediction are given in Table 1 (along with data for plastic beads used in visualisation experiments). Two planes are analysed: one transverse plane mid-way along the straight, and the other at $45^{\circ}$ around the curvature of the bend.

A computational fluid dynamics code [Fluent version 5.4, Fluent Inc., Centerra Research Park, 10 Cavendish Court, Lebanon, New Hampshire 03766, United States of America] with an algebraic slip mixture model and a discrete phase model was used to track the sand particles within the horizontal bend and straight geometries. The authors used the well-respected $\boldsymbol{k}$ - $\boldsymbol{\varepsilon}$ turbulence closure model (where $\boldsymbol{k}$ refers to the turbulent kinetic energy $(\mathrm{J})$ and $\boldsymbol{\varepsilon}$ refers to its local rate of dissipation $(\mathrm{J} / \mathrm{s})$ ). The development of two-equation turbulence models in the 1970s is well described by Spalding and Launder [27]. Modest computation times with the $\boldsymbol{k}-\boldsymbol{\varepsilon}$ model routinely 
allowed several sets of conditions to be tested in the compass of a single day. Validations of the model for swirling pipeflow are described by Jones and Ganeshalingam [28].

By tracking the path of sand particles through the bend geometry, the number of particles which became "trapped" on the surface (i.e. those that may represent impact) could be evaluated. The starting locations of the particles were randomly distributed at the inlet to the bend geometry. This analysis showed that on average between 8 and $20 \%$ of particles impinge on the bend surface at plane $45^{\circ}$ while $40 \%$ impinge on the straight at plane $0^{\circ}$. Although this is a simple model which assumes no inlet swirl or particle cloud shielding of the surface or possible particle-particle interactions, it does provide an order of magnitude check on the likely probability of impingement rates and allows a typical erosion efficiency $\phi$ to be set at 0.2 .

Table 1 represents two cases in which the particle burden would be asymmetrically placed.

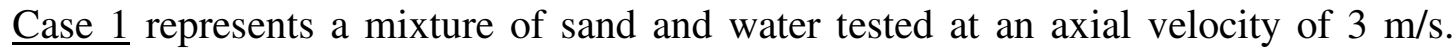
These were used for the erosion study.

$\underline{\text { Case } 2}$ represents a mixture of water and barium-doped plastic beds at a relatively low axial velocity $(1 \mathrm{~m} / \mathrm{s})$. These were only used for the flow visualisation and ERT experiments.

To obtain the near wall particle velocities the Fluent v5.4 CFD code with an algebraic slip mixture model was used and the results, for case 1, plotted in Figure 1. For an inlet free stream velocity of $3 \mathrm{~m} / \mathrm{s}$ and spherical particles of $1 \mathrm{~mm}$ diameter with a density of $2650 \mathrm{~kg} / \mathrm{m}^{3}$ and $\mathrm{R}_{\mathrm{c}} / \mathrm{D}=1.2, \mathrm{D}=77.8 \mathrm{~mm}$, the average near wall particle velocity was $2.22 \mathrm{~m} / \mathrm{s}$ or $74 \%$ of free steam velocity for the bend plane at $45^{\circ}$. 


\section{Experimental work}

\subsection{Case 1: Pilot scale work on sand and water}

The pilot-scale sand/water rig is sketched in Figure 2. The pipe loop was constructed in the horizontal plane with a valve to allow flow to be diverted to another loop as necessary. A high power gate stirrer was installed to help distribute the solids in the tank. Pipe components were made of AISI 304L stainless steel with a nominal wall thickness of $5 \mathrm{~mm}$. The pipes were of $80 \mathrm{~mm}$ nominal bore, although the actual mean of a series of measurements was $77.8 \mathrm{~mm}$. Bend 65 had the greatest curvature of the whole loop $(R c / D=1.2)$ and, with its upstream straight 43 , is analysed for its flow characteristics and propensity to wear in this paper. Details of these components are given in Figure 3.

\subsection{Sand erodent details}

The sub-angular to sub-rounded silica sand used, in both pilot loop and laboratory jet impingement tests, was from the Leighton Buzzard Quarry of Hepworth Minerals and Chemicals Ltd and had a size distribution as shown in Figure 4. The density of the silica sand was $2650 \mathrm{~kg} \mathrm{~m}^{-3}$ with a nominal hardness of $1100 \mathrm{HV}$.

\subsection{Sand volume fraction calibration}

A calibration study was first undertaken to ascertain the actual concentration (by volume) in the pipe ("in situ" concentration) when a given bulk quantity of sand had been loaded. A full load of water (1500 litres) was metered and the large gate stirrer in the tank was started before a series of weights of sand were added. Large-bin samples were taken from the circulating mixture to calculate the in situ concentration for the known total concentration (obtained from the total volume of sand and the total volume of water). This calibration was then used to determine the sand weight required for a given in situ concentration (by volume). 


\subsection{Sand competancy}

Following the calibration study a series of tests were done to investigate the competance of the sand erodent after prolonged circulation in the rig. After each test, a sample of the sand was taken. The sample was classified by size so that the performance of different size classes could be examined. A small subsample of each size class (usually about 100 grains) was carefully separated and imaged with a microscope. A simple estimate of the curvature of the sharp corners was provided by the circularity metric.

Circularity $=\frac{(\text { particle perimeter })^{2}}{(\text { particle } \text { area })}$

A further aspect of degradation was expected to be an equalising effect on the dimensions of the grains. Long grains would be expected to be shortened by the attrition process. This effect could be expressed as an aspect ratio. This metric uses the longest axial dimension of the plane profile of the particle and the maximum width measured in this plane at right angles to this axis.

$$
\text { Aspect } \text { Ratio }=\frac{\text { length of the major axis }}{\text { width measured at right angles to the major axis }}
$$

Hence degradation could be shown as a locus on a graph of mean circularity (over the subsample) against mean aspect ratio. A typical locus is shown in Figure 5 for a test in which sand at $10 \%$ concentration by volume was pumped at $3 \mathrm{~m} / \mathrm{s}$ for 14 hours. The expected reduction in both aspect ratio and circularity was evident in most size classes (bearing in mind the smallness of the subsample for microscope imaging), but for the largest size class a slight increase in aspect ratio was indicated in some samples. For the same test the used sand showed a reduction of the median size $\boldsymbol{S}_{50}$ from $940 \mu \mathrm{m}$ to $920 \mu \mathrm{m}$.

Tests were carried out at a range of concentrations from $5 \%$ by volume to $18 \%$ by volume and velocities from $3 \mathrm{~m} / \mathrm{s}$ to $7 \mathrm{~m} / \mathrm{s}$. In most cases the shape change was significant whatever the conditions. It was concluded that sand should be changed at the most frequent interval (i.e. after every test) to ensure its efficiency as an erodent. 
For the pilot study, a slurry of $10 \%$ concentration by volume of sand in water $(\mathrm{pH} 10$, $\mathrm{Cl} 500 \mathrm{ppm}$ ) was circulated around the loop at a flowrate of $0.01 \mathrm{~m}^{3} / \mathrm{s}$ to give a mean flow velocity of $3 \mathrm{~m} / \mathrm{s}$ over 210 hours. Following a test (7 or 14 hours of running at a specific test condition), the sand slurry was emptied and retained in tanks. Sand was sampled for degradation tests as described above before being discarded. The loops were then carefully dismantled for cleaning and weighing.

\subsection{Gravimetric technique}

Pipe sections were prepared for weighing by firstly thoroughly rinsing with water to remove any sand and then cleaned with warm 5\% citric acid to remove calcite deposits on internal surfaces. This was necessary to allow the change in mass of the pipe sections to be attributed solely to erosion. The pipes were then allowed to air dry, usually overnight, prior to weighing.

Weighing was carried out on a bespoke apparatus consisting of four Ohaus® Explorer electronic balances controlled by means of the RS232 interface and a single personal computer. The final mass of each pipe section could be compared to the initial mass at the start of the test series to provide a total mass loss for the 210 hour runtime.

\subsection{Case 2: Experimental setups for E.R.T. using bead/water mixtures}

A 50mm bore hydraulic conveying pipe loop composed of transparent 1 metre flanged sections in a vertical plane was used for the experiments. The pumped media comprised water and cylindrical non-conductive beads (diameter $2 \mathrm{~mm}$ and relative density 1.45) as a simulant for an industrial settling slurry (coal particles have a relative density of approximately 1.4 for example). ERT sensors were fitted at $150 \mathrm{~mm}, 370 \mathrm{~mm}, 885 \mathrm{~mm}$ and $1150 \mathrm{~mm}$ separately and away from the outlet of a straight pipe giving $\boldsymbol{L} / \boldsymbol{D}$ ratios of 3,7.4, 17.7 and 23. $\boldsymbol{L} / \boldsymbol{D}$ ratio is defined as the ratio of the downstream distance $(\boldsymbol{L})$ to the pipe diameter $(\boldsymbol{D})$. A series of concentrations $(3 \%, 6 \%, 9 \%$ and $12 \%)$ and flow velocities $(0.5,1.0,1.5,2.0$ and $2.5 \mathrm{~m} / \mathrm{s})$ were used in the experiments. Each plane of ERT sensors was fitted with 16 electrodes, evenly distributed along the inner wall of the pipe. The size of each stainless steel electrode 
was $6 \mathrm{~mm}$ wide by $18 \mathrm{~mm}$ in length. Figure 6 shows the installed ERT sensor at $\boldsymbol{L} / \boldsymbol{D}=$ 3.

Measurements were made using a commercial ITS-P2000 ERT system [14]. A current injection protocol based on excitation of adjacent electrodes using $10 \mathrm{kHz}$ alternating current was used. The gains of pre-amplifiers for all measurement were acquired by automatic calibrations. Both single plane and the two-plane arrangements were used in measurements. Images were reconstructed using a sensitivity-coefficient back-projection algorithm.

\subsection{Laboratory scale work}

The jet impingement test used a $5.4 \mathrm{~mm}$ diameter jet nozzle to generate a free jet of $3.5 \mathrm{~m} / \mathrm{s}$ that impinged at $90^{\circ}$ onto a planar sample of AISI 304L stainless steel. The test was conducted for 6 hours with a slurry (pH 10, Cl 500 ppm) containing $4.1 \%$ sand by volume. The bend, straight and the planar samples had an initial surface roughness of $R_{a}$ of $6.5 \mu \mathrm{m}$ and $0.28 \mu \mathrm{m}$ respectively. The jet impingement rig was designed according to a similar rig developed at the University of Cambridge [15] and is a once through system (avoiding the effects of recirculation and the blunting or fragmentation of sand particles). The test solution was circulated around the rig via a centrifugal pump situated at the bottom of the rig. The solid particles from the tank were drawn into the jet through an ejector assembly. It was then mixed with the test solution before exiting through the outer nozzle as a free jet.

\subsection{Gravimetric technique}

Samples pre and post tests were carefully cleaned with warm 5\% citric acid to remove any calcite deposits on internal surfaces and dried before weighing on a precision mass balance to within $\pm 0.1 \mathrm{mg}$.

\section{Analysis of results}

\subsection{Case 1: Gravimetric results from the sand/water pilot rig}


Large differences between values of wear rates per wetted area for different pipe geometries were noted. For example, for bend 65 , it was nearly 5 times greater than the value for the preceding straight 43 (see Table 2).

The mass loss can be viewed as a time series. The slope of this function was positive although the rate appeared to vary during the tests. This variation was noticeable in both components (see Figure 7).

\subsection{Case 2: ERT and flow visualisation results}

A typical flow regime from the flow of $2 \mathrm{~mm}$ non-conductive beads in a conventional cylindrical pipe of $50 \mathrm{~mm}$ bore is revealed by tomographic and photographic evidence in Figure 8. The straight pipe shows that in asymmetric flow a small region of the wetted area can be in use by the particle burden. The evidence from gravimetric tests indicates that use of the wetted area by the particle burden is important in the wall wastage which results from the flow. In another way, the position of the particles in the pipe, and the kinetic energy of those particles, are prime determinants of wear.

\subsection{Surface examinations of internal pipe surfaces}

Post test surface analysis was performed on small samples which had been cut from the pipe sections after the wear test was complete. The overall eroded surface topography was measured using a contact profilometer (Taylor Hobson Form Talysurf 120L, Leicester, UK) while the erosion mechanisms present on the surface were identified using a FEG-SEM.

Figure 9 (a) shows the topography of the top of the straight section 43 of pipe, at position $\mathbf{A}$, there is little or no evidence of erosion damage of the pipe surface. This is to be expected as the flow is asymmetric with most solids being transported in the bottom $25 \%$ of the pipe cross-section minimising sand impingement at position A. Thus, the topography at position $\mathrm{A}$ is that of the 'as-received' state with the original manufacturing marks still visible. In contrast, Figure 9 (b) shows the topography at position $\mathbf{E}$ (bottom) and the surface has been clearly eroded and/or polished (removal 
of manufacture marks, etc.) resulting in a rippled surface finish with a wavelength of approximately $0.5 \mathrm{~mm}$. The erosion is likely to result from low angle $\left(<6^{\circ}\right)$ impingements as predicted by the CFD model shown in Figure 1(b).

SEM investigations of straight pipe erosion mechanisms are shown in Figures 10-11. Figure 10 shows the surface at position $\mathrm{A}$ in the straight pipe at different magnifications and is consistent with that of the as-manufactured surface finish. There appears to be no significant erosion impact damage although a few individual impact craters are seen due to impacts from the relatively few sand particles that are entrained into the energetic upper fluid flow.

Figure 11a shows that the as-manufactured surface finish has been removed at position $\mathrm{E}$ in the straight pipe. In Figure $11 \mathrm{~b}$, the impact features reveal that the erosion processes occurred by a simultaneous plastic deformation and micro-cutting of the stainless steel pipe surface, similar to type II cutting mentioned by Hutchings when erodent rolls backwards on impact and efficiently machine the surface [16].

Figure 12 shows the typical topography of bend 65 at position $\mathbf{E}$ (bottom) of the $45^{\circ}$ plane while Figure 13 shows the SEM micrographs. The surface has been clearly eroded with evidence of low angle impingements with extensive plastic deformation and cutting (type II) resulting in the removal of the as-manufactured surface morphology. The damage patterns are consistent with the impact angles predicted by the CFD modelling and shown in Figure 1 (b). In Figure 12 there are two scales of damage visible. A large ripple pattern with a $2 \mathrm{~mm}$ wavelength perpendicular to the flow direction and $12 \mu \mathrm{m}$ in depth. Within these features are numerous small ripples again perpendicular to the flow direction but $25 \mu \mathrm{m}$ in wavelength and only $0.5 \mu \mathrm{m}$ deep. Figure 14 shows that both these ripple features are a result of multiple craters from sand impacts. Some impact scars are clearly seen and are 1-2 $\mu \mathrm{m}$ wide and $5 \mu \mathrm{m}$ long (far smaller contact area that the nominal size of the sand particles would suggest). 


\subsection{Discussion of mechanisms/patterns of surface damage}

The formation of waves or ripples on the surface of materials subject to small-angle impingement erosion has been widely observed and models for its formation described [17-21]

Typically ripple formation occurs in a uniform and steady fluid flow. In addition, ripples do not form immediately when the surface is eroded, however, there is a gradual transition from a condition in which single erosion events determine the surface roughness to one in which well-developed ripples dominant. A descriptive model is schematically presented in Figure 14, based on the interaction between eddies and surface profile [21]. The model is linked to the boundary layer fluid flow and goes through a number of distinct stages. It is known that flow is impeded by friction at the pipe-liquid interface; hence the fluid velocity at the surface is far slower than the bulk fluid. This velocity difference increases with increasing bulk velocities and gives rise to shear forces. These in turn result in turbulence which is expressed as eddies at the pipe surface (Figure 14a). The surface micro-roughness has a significant influence on the size and stability of these eddies.

Initially the eddy pattern is determined by the roughness generated by the final machining operation. (Figure 14a). The ability of the sand particles to erode is largely determined by the bulk flow. The initial surface roughness is thus replaced by the roughness resulting from individual erosion events. In a ductile material, such as stainless steels, it will be the impact scar dimensions (Figure 14b). These in turn give rise to a new eddy pattern. During the erosion process, sand particles have to pass through these eddies and are thereby deflected. The eddy pattern determines the angle of impact and areas of increased sand particle impact. The concentration of damage at specific points results in the establishment of a ripple pattern, reflecting the turbulence pattern. The surface waviness increases until a steady state is reached at which point the surface continues to wear but the wavelength and shape remain constant (Figure 14c). The final waviness is thus a reflection of the conditions that 
the material is exposed. The more severe the condition the greater is the turbulence in the boundary layer and hence the larger is the surface waviness.

Comparing the Talysurf images for two different pipe sections, Figure 9 and Figure 12, it is clearly evident that the most intense ripple pattern occurred on bend 65 possibly resulting from two scales of turbulent eddies. This is consistent with the above model.

\subsection{Comparison of pilot scale bend erosion rates with the CFD model and the jet impingement tests.}

The linkage between small scale laboratory based erosion data and full scale field data has been studied for as long as small scale laboratory tests have been performed. Due to the non-uniformity of the particulate flow fields encountered in the field and the uncertainties of the solid particle trajectories and their energies on impact with pipe walls successful prediction by simplified laboratory scale tests has, as yet, not been achieved. Indeed, a recent review paper by Clark [22] questions whether, even in a controlled small scale laboratory test, experimentalists actually know enough about what their particles are doing. However, with the advancement in CFD codes some degree of particle tracking is possible and can be used to help predict the location and rate of erosion in both simple and complex flow geometries.

An attempt, using such CFD derived flow field parameters, has been made by the current authors to gain some correlation between small scale slurry jet impingement tests and a full scale bend test. Should strong correlations exist then a direct crossover can be made between the wealth of data obtained from small-scale slurry testing on numerous bulk materials and coatings [23] and full-scale pipe tests. The approach is based on treating particle impacts, size effects and slurry flow modelling as a whole system.

The mass loss of bend 65 after 140 hours was $4.96 \mathrm{~g}$, which gives a volume loss of $620 \mathrm{~mm}^{3}$ by assuming the density of pipe, is $8.00 \mathrm{~g} / \mathrm{cc}$. The mass loss from the planar jet impingement sample after 6 hours was $15.3 \mathrm{mg}$ (or $\sim 2 \mathrm{~mm}^{3}$ ). The volume loss per impact for both cases can be evaluated following the flow diagram in Figure 
15. The erosion model used is based on recognizing that two erosion mechanisms act, cutting and deformation erosion, with discrete models representing each, and has been successfully used by Forder [24] to predict erosion of internal components within choke valves. The cutting erosion model for low impact angles was first proposed by Finnie [25] and later modified by Hashish [2]. The deformation model was proposed by Bitter [26] and is thought applicable at higher impact angles (30$90^{\circ}$ ). As the impingement angles are predicted to be below $10^{\circ}$ the contribution to the overall wear rate from deformation mechanisms can be ignored so the volumetric erosion per impact can be given by the Hashish model only:

$$
V_{u}=\left\{\frac{100}{2 \sqrt{29}} r_{p}^{3}\left(\frac{U_{p}}{C_{k}}\right)^{n} \sin 2 \alpha \sqrt{\sin \alpha}\right\}
$$

where

$$
C_{k}=\sqrt{\frac{3 \sigma R_{f}^{0.6}}{\rho_{p}}}
$$

This model includes important variables such as particle shape and material properties for both particle and target that are typically not considered by earlier simple models.

The $V_{u}$ for the jet impingement test was corrected by using:

$$
\frac{V_{u(\text { bend })}}{V_{u(j e t)}}=\left(\frac{U_{p(\text { bend })}}{U_{p(j e t)}}\right)^{2.54}
$$

For the jet erosion case, hold-up was ignored (zero slip) and all particles are assumed to impinge (erosion efficiency $=100 \%$ ). The $V_{u}$, derived from actual mass loss measurements, of the bend (range between 2.2 and $5.5 \mu \mathrm{m}^{3} / \mathrm{impact}$ ) and jet impingement samples $\left(3.2 \mu \mathrm{m}^{3} /\right.$ impact $)$ are in good agreement. The CFD and erosion model predicts an average $V_{u}$ at the $45^{\circ}$ plane of $5.5 \mu \mathrm{m}^{3} / \mathrm{impact}$ which is expected to be the most severe and thus would have higher erosion rates. 
Comparison of the predicted erosion rates for planes $45^{\circ}$ in the bend and plane $0^{\circ}$ in the preceding straight have been reported earlier by the authors [3] and show that the rates at plane $45^{\circ}$ are approximately 3 times those in the straight. This compares reasonably well with the gravimetric results from the loop tests, which integrate all planes in the components, that show a 5 times difference, see Table 3.

\section{Conclusions}

The erosion of an upstream straight followed by a bend with a radius of curvature of 1.2 bore diameters within a $78 \mathrm{~mm}$ diameter pipe test loop handling water-sand mixtures at $10 \%$ by volume concentrations and at a mean fluid velocity of approximately $3 \mathrm{~m} / \mathrm{s}$ have been investigated experimentally on a full scale loop facility and by CFD modelling. The following main conclusions can be drawn:

1. The test sand was found to degrade in the erosion tests of the steel pipework and therefore needs regular replacement.

2. Flow visualisation on a transparent test section and Electrical Resistance Tomography on the straight section verified the particle concentration profiles generated by the CFD code.

3. The erosion predictions derived from the CFD and erosion model were in good agreement with actual damage rates and patterns found in full-scale loop testing.

4. In addition, good agreement was also achieved when the CFD derived erosion rate values were compared to simple laboratory scale water-sand jet impingement tests on planar stainless steel samples.

5. The bend wear patterns were found to consist of various scales of ripples, indicating sand was entrained into varying levels of intensity and scales of turbulence near to the walls. The bends appear to have at least two scales of ripple wavelengths $2000 \mu \mathrm{m}$ and $25 \mu \mathrm{m}$ while the straight appeared to have ripples of $500 \mu \mathrm{m}$ wavelength. 
6. Type II micro-cutting was found to be the dominant erosion mechanism from impacts of angular sand at low angles to the surface.

\section{Nomenclature}

$\alpha \quad$ angle of impingement

$\rho_{p} \quad$ density of particle $\left(\mathrm{kg} / \mathrm{m}^{3}\right)$

$\boldsymbol{\sigma} \quad$ plastic flow stress for target $(\mathrm{Pa})$

$\phi \quad$ erosion efficiency, the ratio of impacting solids to total solids loading (-)

$\boldsymbol{C}_{\boldsymbol{k}} \quad$ cutting characteristic velocity $(\mathrm{m} / \mathrm{s})$

$C_{v} \quad$ Solids volume fraction (-)

$\boldsymbol{D} \quad$ diameter of a pipe bore (m)

$\boldsymbol{F}_{\boldsymbol{m}} \quad$ Average feed per size class of particle $(\mathrm{kg})$

$\boldsymbol{F}_{\boldsymbol{t}} \quad$ Total feed of particles $(\mathrm{kg})$

$\boldsymbol{I}_{\boldsymbol{s}} \quad$ Number of particles per second (-)

$\boldsymbol{L} / \boldsymbol{D} \quad$ length to diameter ratio (-)

$\boldsymbol{M}_{\boldsymbol{p}} \quad$ particle mass $(\mathrm{kg})$

$\boldsymbol{n} \quad$ velocity ratio exponent (2.54 for carbon steel, Hashish [2]), (-)

$\boldsymbol{Q}_{v} \quad$ volume flow rate $\left(\mathrm{m}^{3} / \mathrm{s}\right)$

$\boldsymbol{R} \boldsymbol{c}$ radius of curvature of a pipe bend (m)

$\boldsymbol{R}_{f} \quad$ roundness factor for particle (value 0-1) (-)

$\boldsymbol{r}_{\boldsymbol{p}} \quad$ particle radius $(\mathrm{m})$

$\boldsymbol{S}_{50} \quad\left(\boldsymbol{d}_{50}\right)$ median sieve size of particles $((\mu \mathrm{m}))$

$\boldsymbol{U}_{\boldsymbol{p}} \quad$ particle impact velocity $(\mathrm{m} / \mathrm{s})$

$\boldsymbol{V}$ flow velocity $(\mathrm{m} / \mathrm{s})$

$\boldsymbol{V}_{\boldsymbol{u}} \quad$ Erosion rate $\left(\mu \mathrm{m}^{3} /\right.$ impact $)$

$V_{l} \quad$ Rate of volume loss $\left(\mathrm{m}^{3} \mathrm{~s}^{-1}\right)$

$\boldsymbol{R M C}$ root-mean-cube size between sieves, $\sqrt[3]{\left(\text { upper } \text { size }^{3}+\text { lower } \text { size }^{3}\right) / 2}(\mu \mathrm{m})$

\section{Acknowledgements:}

The authors wish to thank BHR Group for their kind permission to reproduce certain figures and text from papers published in the Hydrotransport conference series. 


\section{References:}

[1] R.J.K. Wood, T.F. Jones, N. Miles and J. Ganeshalingam, Upstream swirl-induction for reduction of erosion damage from slurries in pipeline bends, Wear, 250/1-12 (2001), 771-779.

[2] M. Hashish, An improved model of erosion by solid particles, Proc. $7^{\text {th }}$ Int. Conf. on Erosion by liquid and solid impact, 1988, paper 66, published by Cavendish Laboratory.

[3] R.J.K. Wood., T.F. Jones, J. Ganeshalingam and M. Wang, Erosion modelling of swirling and non-swirling slurries in pipes, Hydrotransport 15, Banff, Canada, BHR Group, 3-5 June 2002, $497 \mathrm{p}$.

[4] R.J.K. Wood, T.F. Jones, J. Ganeshalingam, Erosion in swirl inducing pipes, ASME Fluids Engineering Division Summer Meeting, Montreal, Canada, July 2002, paper FEDSM2002-31287, ASME International.

[5] H.C. Meng and K.C. Ludema, Wear models and predictive equations - their form and content, Wear, 181-183 (1995) 443-457

[6] D.J. Blanchard, P. Griffith and E. Rabinowicz, Erosion of a pipe bend by solid particles entrained in water, Journal of Engineering for Industry, 106 (1984) 213-217.

[7] A. Forder, A Computational Fluid Dynamics investigation into the particulate erosion of oilfield control valves, PhD Thesis, School of Engineering Sciences, University of Southampton, 2000.

[8] A. T. Bourgoyne, Experimental study of erosion in diverter systems due to sand production, SPE/IADC Drilling Conference, (1989) 807, SPE/IADC 18716, Society of Petroleum Engineers.

[9] R. King, B. Jacobs, G. Jones, Factors affecting the design of slurry transport systems for minimum wear, Pipe Protection Conference, Cannes, France, 1991, 67, Elsevier Applied Science, Organised and sponsored by BHR Group.

[10] W. Wiedenroth, An experimental study of wear of centrifugal pumps and pipeline components, Journal of Pipelines, 4 (1984) 223-228.

[11] X. Chen, B.S. McLaury, and S.A. Shirazi, Effects of applying a stochastic rebound model in erosion prediction of elbow and plugged tee, Proceedings of ASME 2002 Fluids Engineering Division Summer Meeting, Montreal, Quebec, Canada, July 14-18, 2002, paper FEDSM2002-31289, ASME International.

[12] M. Ahmed, S.N. Singh and V. Seshadri, Distribution of solid particles in multisized particulate slurry flow through a $90^{\circ}$ pipe bend in horizontal plane, Bulk Solids Handling, 13 (2) (1993) 379-385

[13] H. Clark and C. Burmeister, The influence of the squeeze film on particle impact velocities in erosion, Int. Journal of impact engineering, 12 (1992) 415-426.

[14] G.P. Lucas, J. Cory, R. Waterfall, W.W. Loh and F.J. Dickin, Measurement of the solids volume fraction and velocity distributions in solids-liquid flows using dual-plane electrical resistance tomography, Journal of Flow Measurement and Instrumentation, 10 (4) (1999) 249258. 
[15] J.B. Zu and I.M. Hutchings, Design of a slurry erosion test rig, Wear, 140 (1990) 331344.

[16] I.M. Hutchings, Tribology: Friction and Wear of Engineering Materials, Arnold, 1992, 175.

[17] G.R. Abrahamson, Permanent periodic surface deformations due to a travelling jet, J. Appl. Mech. E, 83 (1961) 519-528.

[18] A.K. Cousens and I.M. Hutchings, in J.E. Field and N.S. Corney (eds), Proc, $6^{\text {th }}$ Int. Conf. on Erosion by Liquid and Solid Impact, Cavendish Laboratory, Cambridge, 1983, Paper 41, published by Cavendish Laboratory.

[19] G. Carter, The mechanism of ripple generation on sandblasted ductile solids, M.J. Nobes and K.I. Arshak, Wear, 65 (1980) 151-174.

[20] J. Stringer and I.G. Wright, in J.E. Field and J.P. Dear (eds), Proc. $7^{\text {th }}$ Int. Conf. on Erosion by Liquid and Solid Impact, Cavendish Laboratory, Cambridge, 1987, Paper 47., published by Cavendish Laboratory.

[21] A. Karimi and R.K. Schmid, Ripple formation in solid liquid erosion, Wear, 156 (1992) 33-47.

[22] H. Clark, Particle velocity and size effects in laboratory slurry erosion measurement, Tribology International, 35 (2002) 617-624.

[23] R.J.K. Wood, The erosion performance of candidate internal coatings for slurry handling and pipeline transport, Proc of Hydrotransport 14, Maastricht, Holland, 1999, 699, Professional Engineering Publishing.

[24] A. Forder, M.T. Thew, D. Harrison, A numerical investigation of solid particle erosion experienced within oilfield control valves, Wear 216 (1998) 184-193

[25] I. Finnie, Some observations on the erosion of ductile metals, Wear, 19 (1972) 81-90.

[26] J.G.A. Bitter, A study of erosion phenomena: Part I, Wear, 6 (1963) 5-21.

[27] D.B. Spalding and B.E. Launder, Turbulence models and their application to the prediction of internal flows, Heat and Fluid Flow, 2 (1972), 43-54

[28] T.F.Jones and J.Ganeshalingam, Towards optimal swirl-inducing pipe, $15^{\text {th }}$ International Conference on Hydrotransport, Banff, Canada: 3-5 June 2002, 457-468, BHR Group. 
Table 1. Values of parameters used in the computational models

\begin{tabular}{|lll|}
\hline Parameters & $\begin{array}{l}\text { Value for Case 1 } \\
\text { Sand /water }\end{array}$ & $\begin{array}{l}\text { Value for Case 2 } \\
\text { beads/water }\end{array}$ \\
Volume flow rate $Q_{v}\left(\mathrm{~m}^{3} / \mathrm{s}\right)$ & 0.01 & 0.002 \\
Pipe bore $(\mathrm{m})$ & 0.078 & 0.05 \\
Particle velocity on entry $U_{p}(\mathrm{~m} / \mathrm{s})$ & 3.0 & 1.0 \\
Particle density $\rho_{p}\left(\mathrm{~kg} / \mathrm{m}^{3}\right)$ & 2650 & 1480 \\
Roundness factor $R_{f}$ & 0.5 & 0.5 \\
Plastic flow stress $\sigma(\mathrm{Pa})$ & $1.0 \mathrm{E}+09$ & $1.0 \mathrm{E}+09$ \\
Particle radius $r_{p}(\mathrm{~m})$ & $5.0 \mathrm{E}-04$ & $1.0 \mathrm{E}-03$ \\
Velocity ratio exponent $n$ & 2.54 & 2.54 \\
Particle mass $M_{p}(\mathrm{~kg})$ & $1.4 \mathrm{E}-06$ & $6.2 \mathrm{E}-06$ \\
\hline
\end{tabular}

\begin{tabular}{|c|c|c|c|}
\hline \multicolumn{4}{|c|}{ Table 2 : Total Mass Loss and Estimated Wear Rate } \\
\hline Component & $\begin{array}{c}\text { Final mass loss } \\
(210 \text { hours })\end{array}$ & $\begin{array}{c}\text { Rate of wear } \\
(\mathrm{g} / \mathrm{hr})\end{array}$ & $\begin{array}{c}\text { Rate of wear } \\
\text { per wetted area } \\
\left(\mathrm{g} \mathrm{hr}^{-1} \mathrm{~m}^{-2}\right)\end{array}$ \\
\hline Bend & 9.45 & 0.05 & 0.78 \\
\hline Straight & 4.75 & 0.02 & 0.16 \\
\hline
\end{tabular}


Table 3. Values of Parameters used in evaluating erosion rates from actual bend mass loss data, CFD predictions and jet impingement tests.

\begin{tabular}{|c|c|c|c|}
\hline & $\begin{array}{l}\text { Bend } \\
\text { with } \\
\text { Rc/D=1.2 } \\
\end{array}$ & $\begin{array}{l}\text { CFD + erosion } \\
\text { model of } \mathrm{Rc} / \mathrm{D}=1.2 \\
\text { bend }\end{array}$ & Jet impingement \\
\hline \multicolumn{4}{|l|}{$\begin{array}{l}\text { Experimental } \\
\text { measurements }\end{array}$} \\
\hline Mass loss (g) & 4.96 & & 0.0153 \\
\hline Volume loss $\left(\mathrm{mm}^{3}\right)$ & 620 & & 2.0 \\
\hline \multicolumn{4}{|l|}{ Calculations } \\
\hline Bore $(\mathrm{mm})$ & 77.8 & 77.8 & 5.4 \\
\hline Inlet particle velocity $(\mathrm{m} / \mathrm{s})$ & 3.0 & 3.0 & 3.5 \\
\hline $\begin{array}{l}\text { Near wall particle velocity } \\
U_{p}(\mathrm{~m} / \mathrm{s})\end{array}$ & 2.22 & 2.22 & 3.5 \\
\hline $\begin{array}{lll}\begin{array}{l}\text { Volumetric } \\
\left(\mathrm{m}^{3} / \mathrm{s}\right)\end{array} & \text { flowrate } & Q_{v} \\
\end{array}$ & 0.0106 & N/A & $8 \times 10^{-5}$ \\
\hline $\begin{array}{l}\text { Solids concentration by } \\
\text { volume } C_{v}\end{array}$ & 0.1 & 0.1 & 0.041 \\
\hline Solids flowrate $Q_{s}\left(\mathrm{~m}^{3} / \mathrm{s}\right)$ & 0.00106 & N/A & $3.28 \times 10^{-6}$ \\
\hline $\begin{array}{l}\text { RMC diameter of particle } \\
(\mu \mathrm{m})\end{array}$ & 995.4 & 995.4 & 995.4 \\
\hline $\begin{array}{ll}\text { Number of impacts } I_{S} \\
\text { (impacts/second) }\end{array}$ & $2.8 \times 10^{6}$ & N/A & $8.72 \times 10^{3}$ \\
\hline Erosion efficiency $\phi(\%)$ & $8-20$ & 100 & 100 \\
\hline Test duration $t$ (hours) & 140 & N/A & 6 \\
\hline $\begin{array}{l}\text { Raw erosion rate } V_{u} \\
\left(\mu \mathrm{m}^{3} / \mathrm{impact}\right)\end{array}$ & $2.2-5.5$ & 5.5 & 10.2 \\
\hline $\begin{array}{l}\text { Corrected erosion rate } V_{u} \\
\text { for } \\
U_{p}=2.22 \mathrm{~m} / \mathrm{s}\left(\mu \mathrm{m}^{3} / \mathrm{impact}\right)\end{array}$ & $2.2-5.5$ & 5.5 & 3.2 \\
\hline
\end{tabular}


(a)

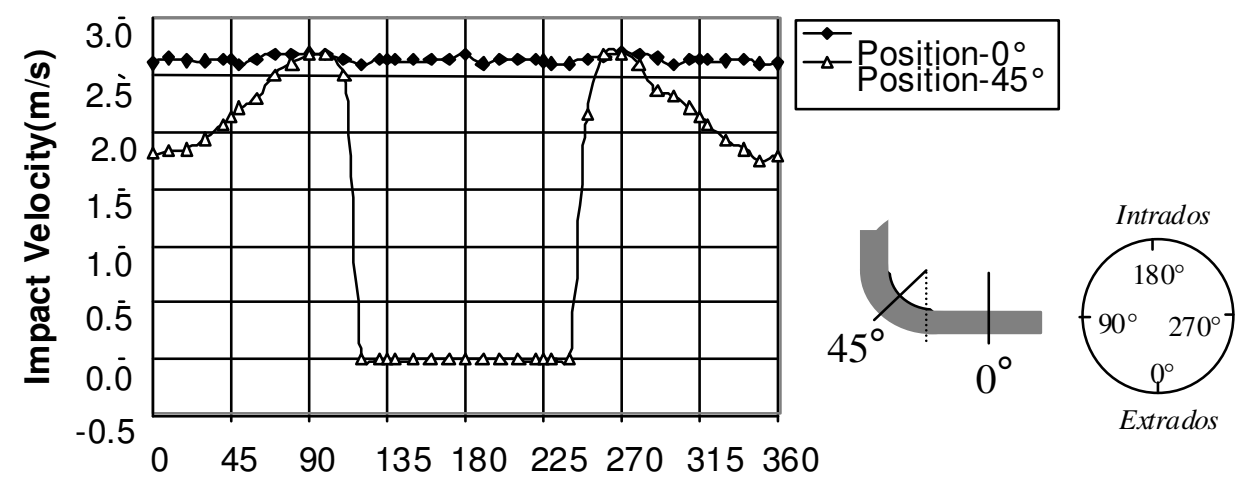

Angle within plane $\left({ }^{\circ}\right)$

(b)

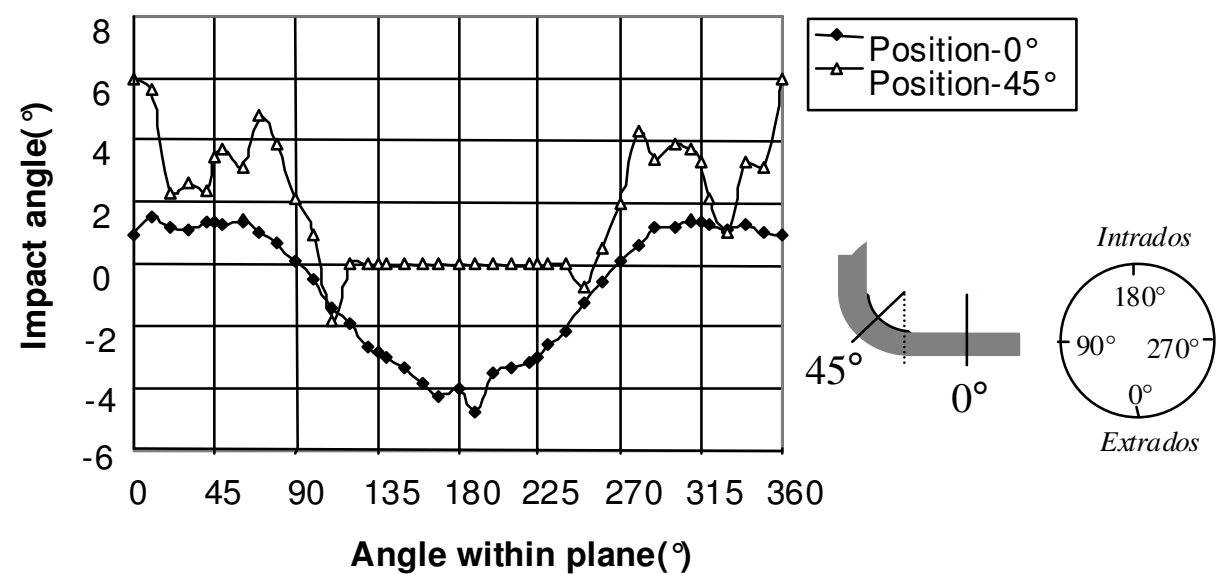

Figure 1: Model results for planes on the straight $\left(0^{\circ}\right)$ and $45^{\circ}$ around the bend. (a) Impact velocity of sand particles with the inner surface of the pipe wall for case 1. (b) Angle of impact of particles with inner surface of the pipe wall. Mean inlet free stream velocity of $3 \mathrm{~m} / \mathrm{s}, 10 \%$ by volume solid concentration and sand diameter of $1 \mathrm{~mm}$. 


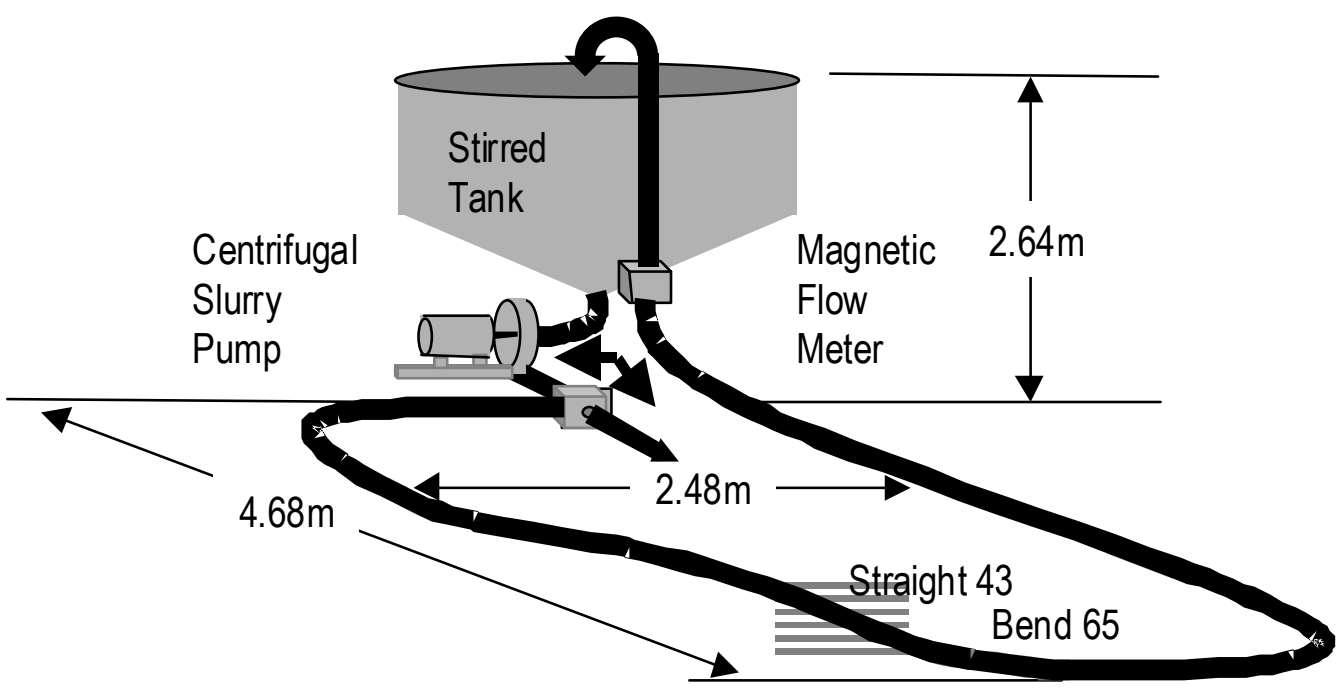

Figure 2: Slurry loop layout showing approximate dimensions and approximate position of components straight 43 and bend 65 

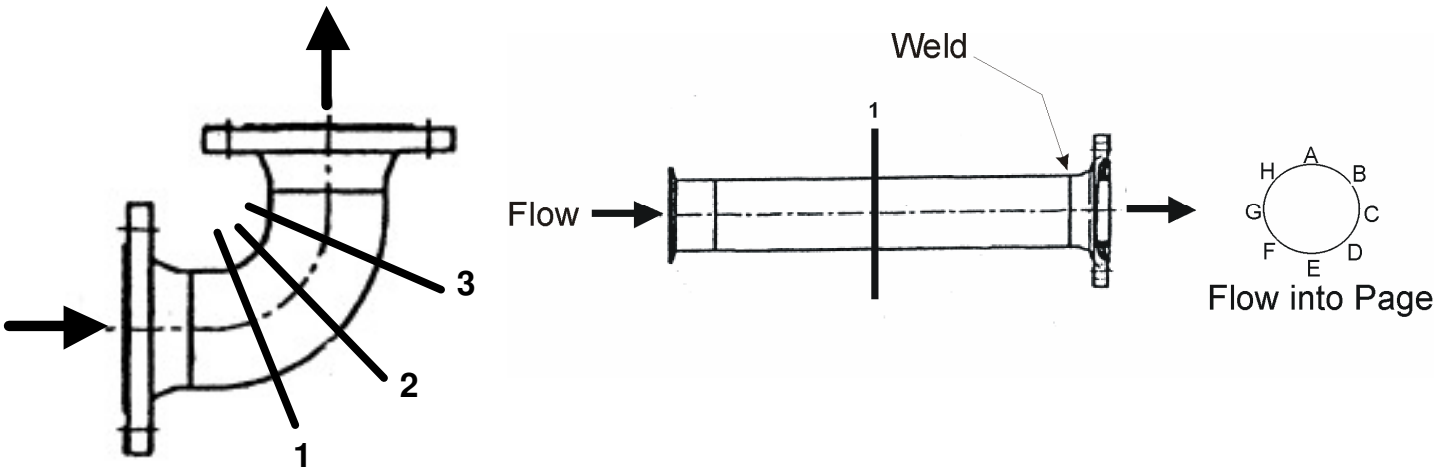

Figure 3 Drawings of bend 65 and straight section 43 used in the working section. 


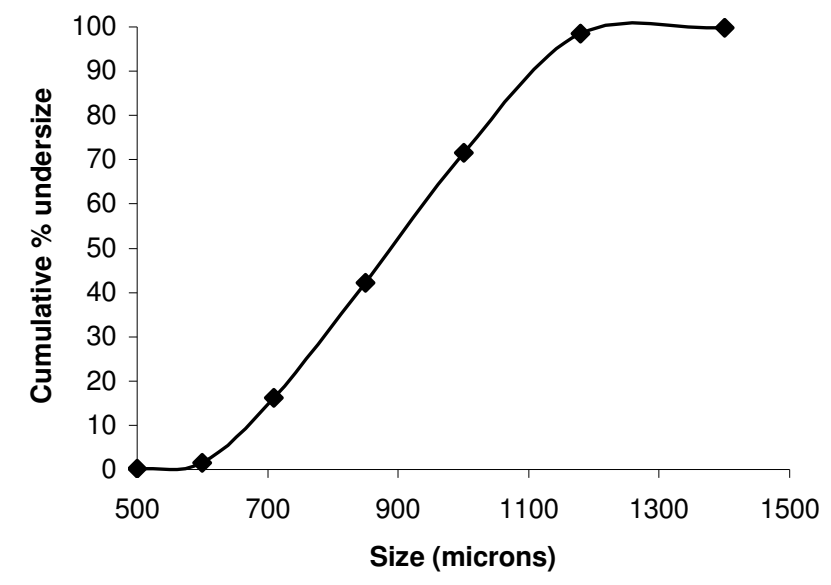

Figure 4: Sand size distribution for the bend and jet impingement tests 


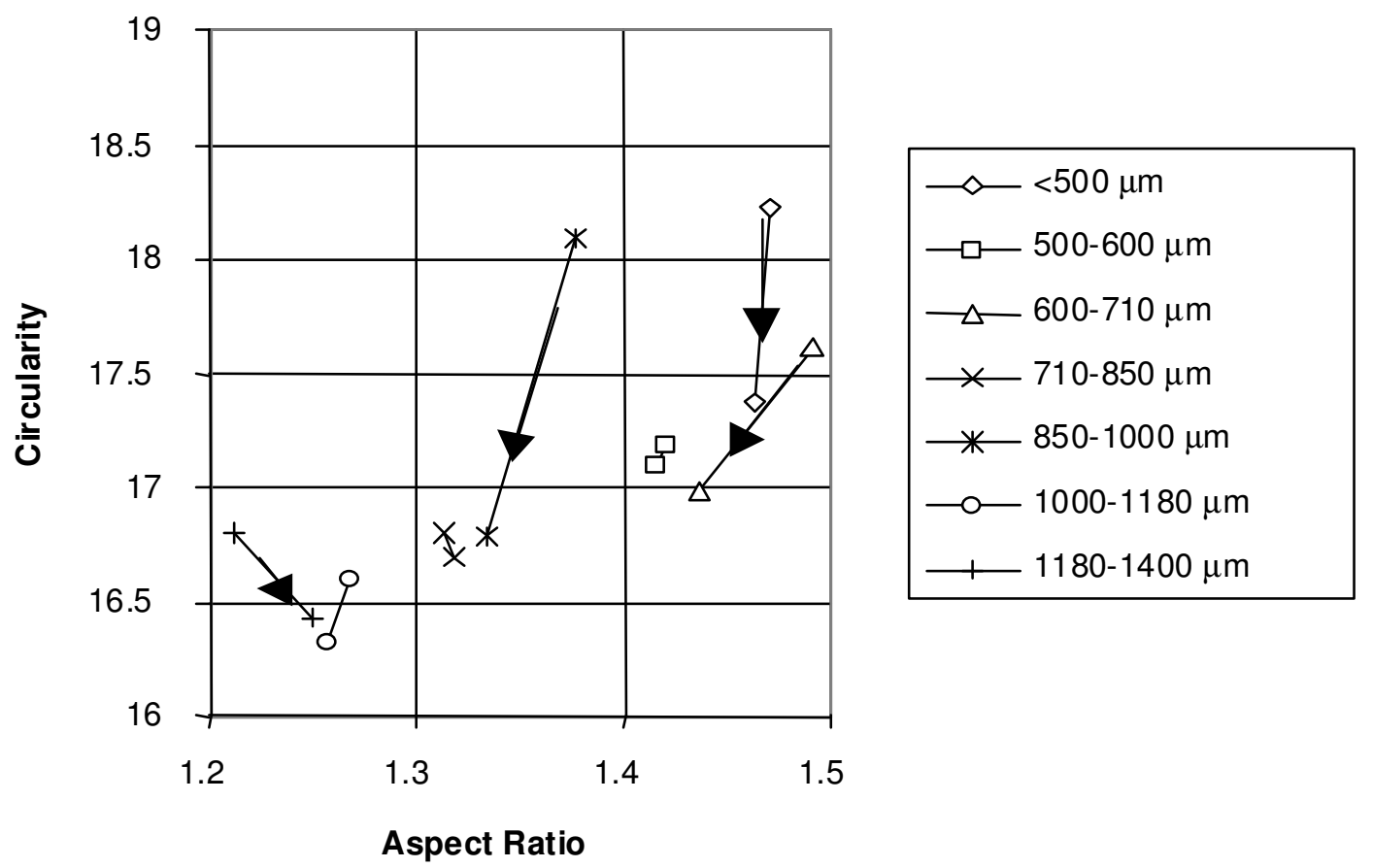

Figure 5: Degradation of particle shape by size class after 14 hours of pumping (Concentration of sand $10 \%$ by volume, velocity $3 \mathrm{~m} / \mathrm{s}$ ) 


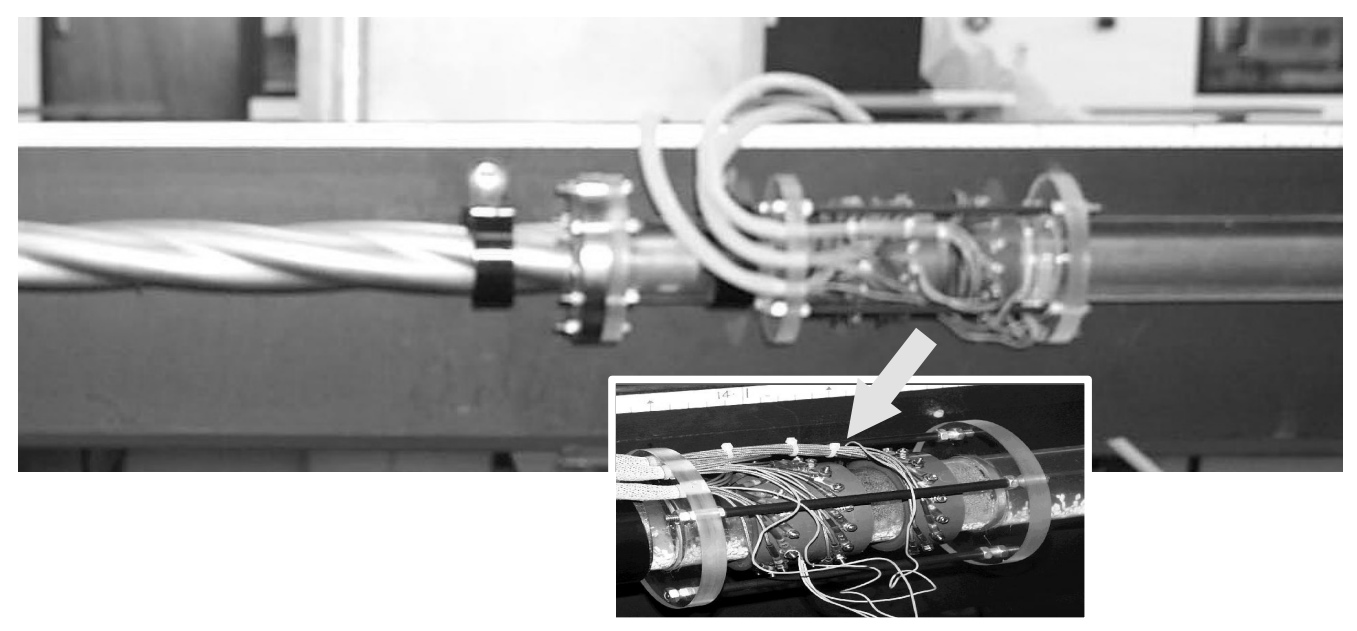

Figure 6: Typical ERT location (after swirl pipe in this case) and the tomographic sensor 


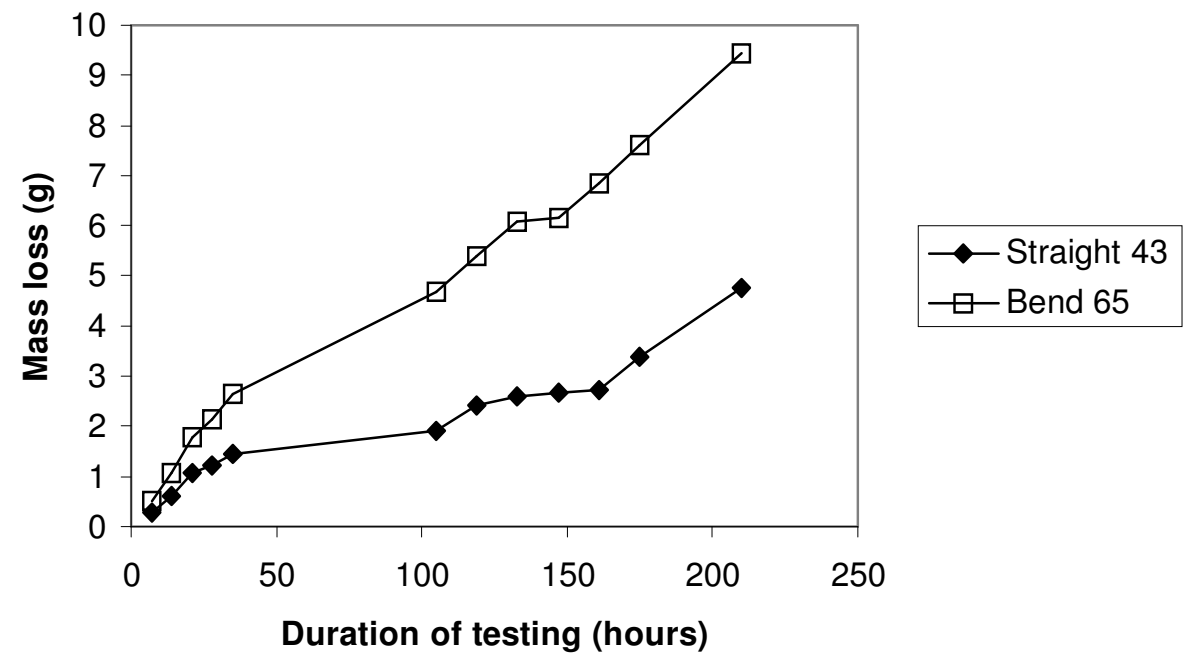

Figure 7: Wall wastage for pilot scale tests, $1 \mathrm{~mm}$ sand, $10 \%$ by volume and $3 \mathrm{~m} / \mathrm{s}$ flow velocity 


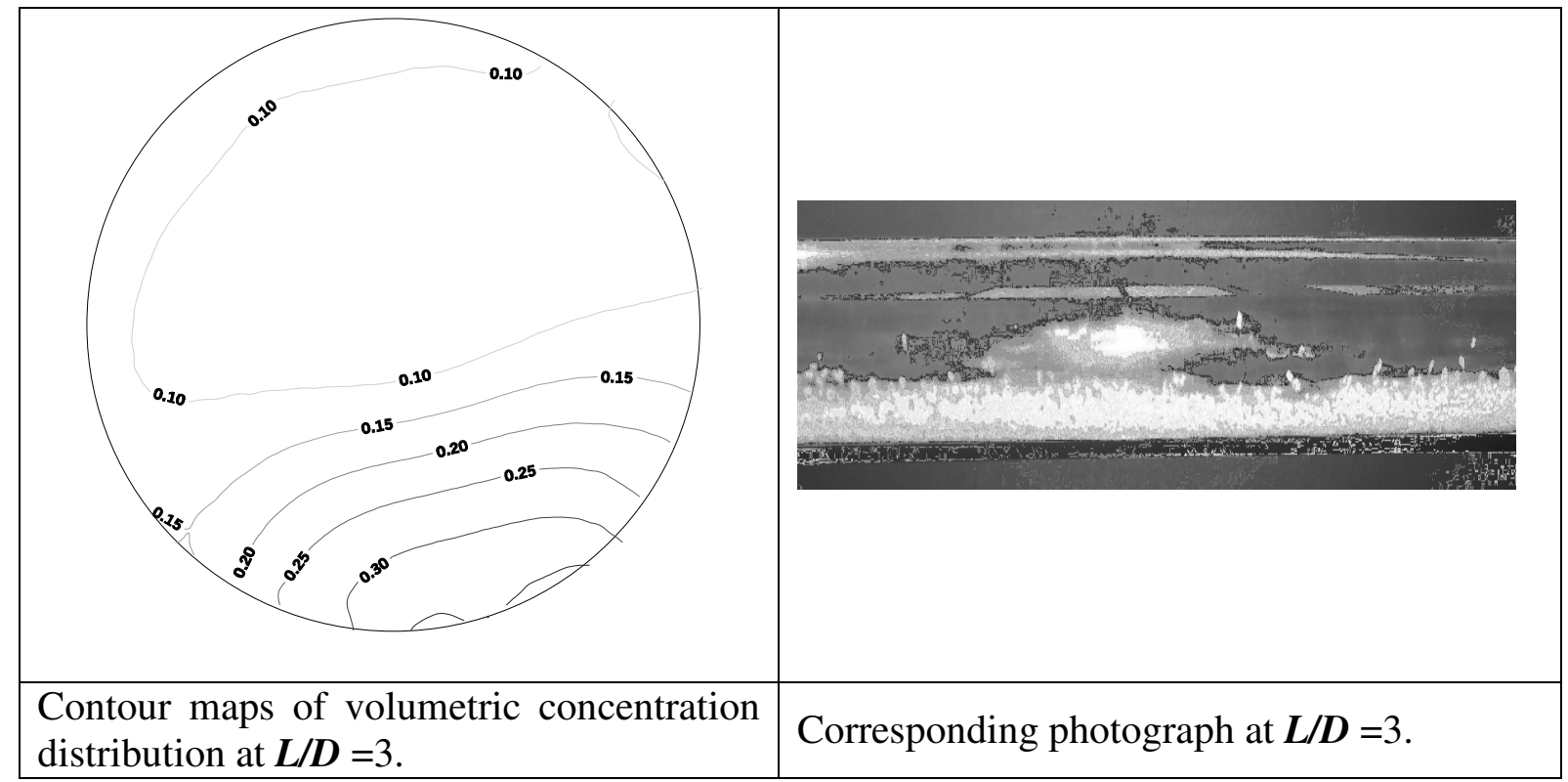

Figure 8: Tomographic and photographic evidence of the flow patterns of a bead-water mixture comprising $2 \mathrm{~mm}$ beads of relative density 1.45 with mean concentration $6 \%$ by volume, and overall mean flow velocity $1 \mathrm{~m} / \mathrm{s}$ 
(a) Straight position $1 \mathrm{~A}$ top

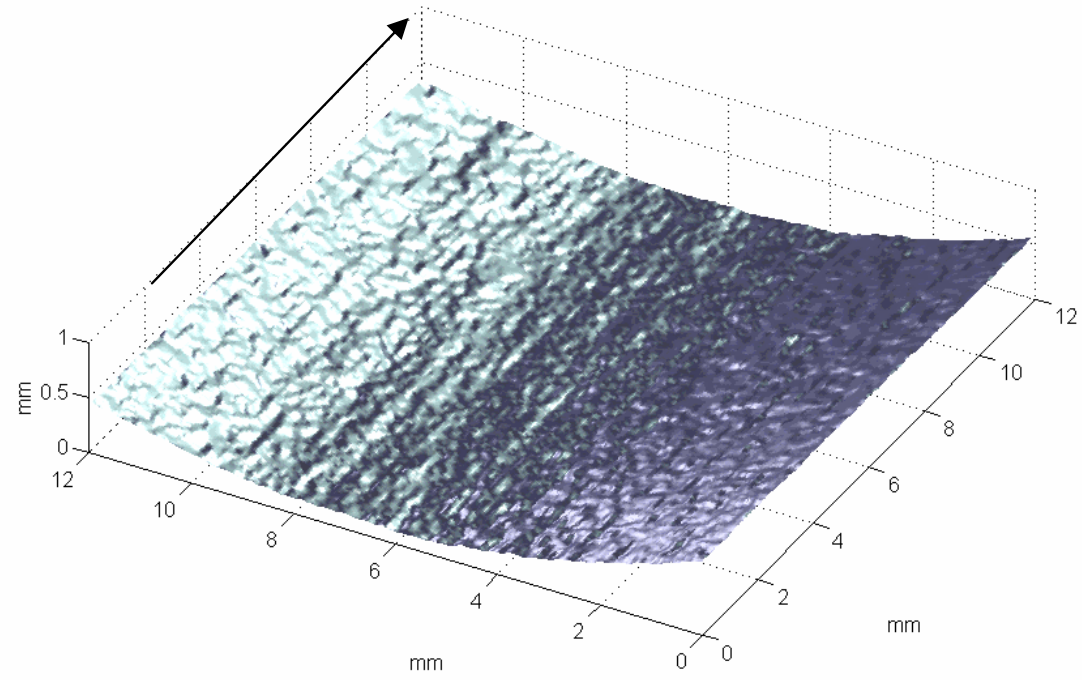

(b) Straight position 1E bottom

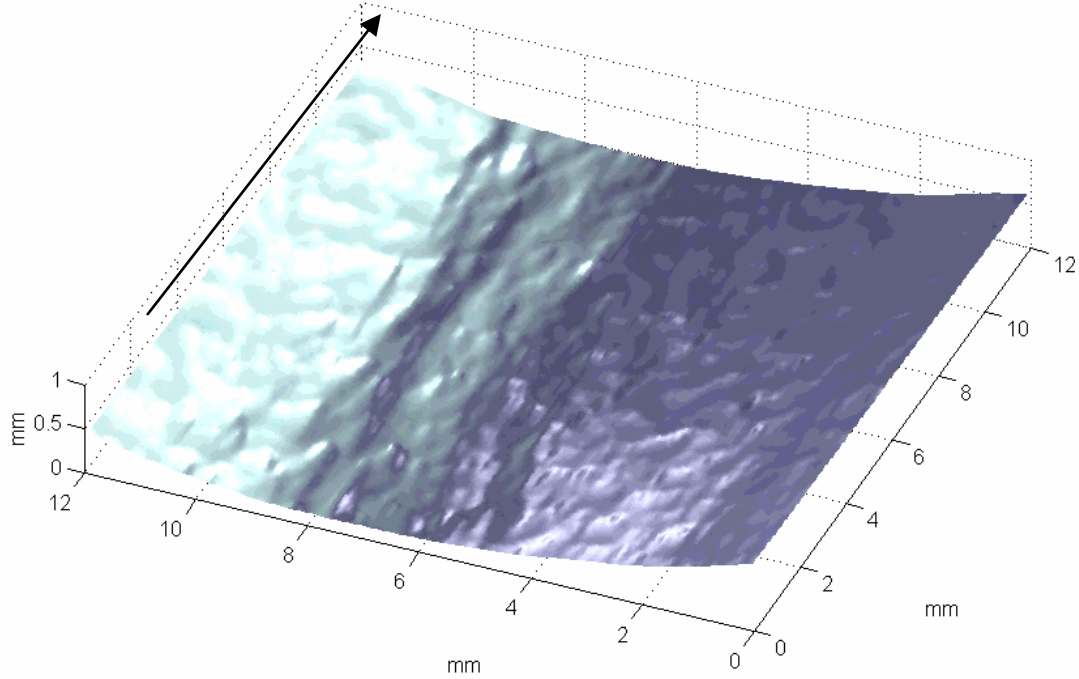

Figure 9: 3D Talysurf images of the straight pipe section after 210 hrs. (arrows indicate flow direction) 
(a)

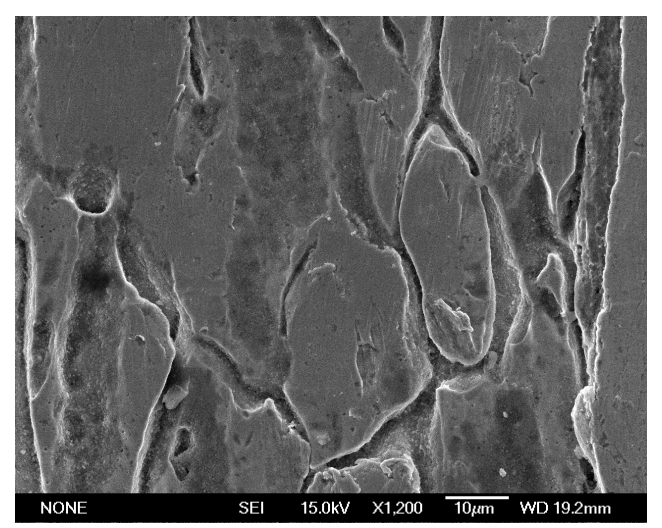

(b)

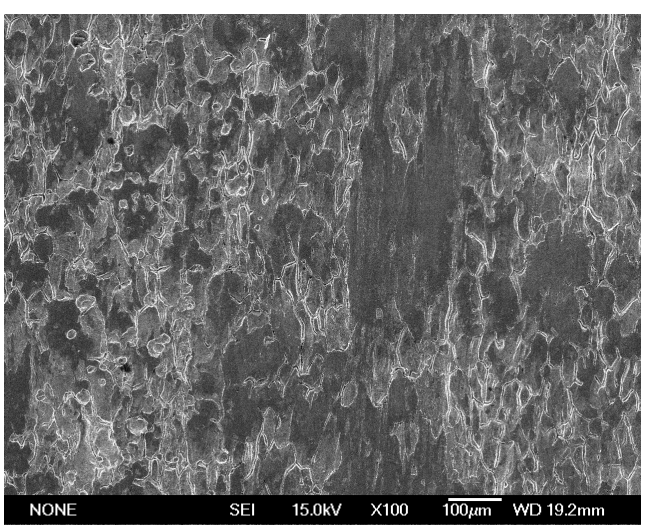

Figure 10: SEM micrographs showing surface morphology of straight position A (top) (after $210 \mathrm{hrs}$.).

(a)

(b) 

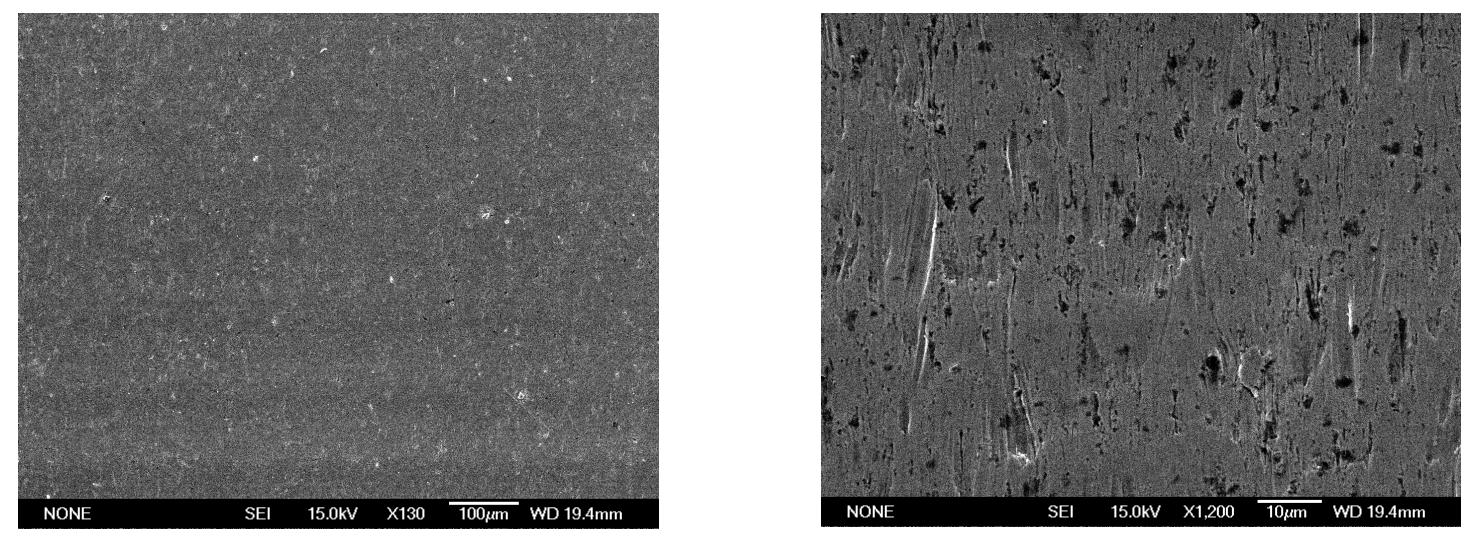

Figure 11: SEM micrographs showing the surface morphology of the straight position $\mathbf{E}$ (top) (after 210 hours). 


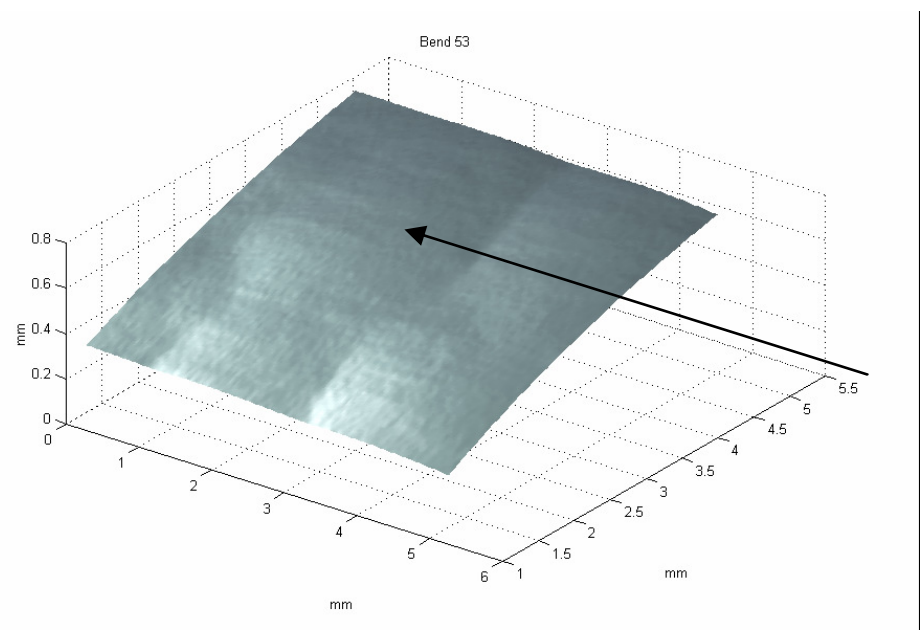

Figure 12: 3D Talysurf image of a replica of the bend section at plane $45^{\circ}$ after 140 hours (arrow indicates flow direction) 
(a)

(b)
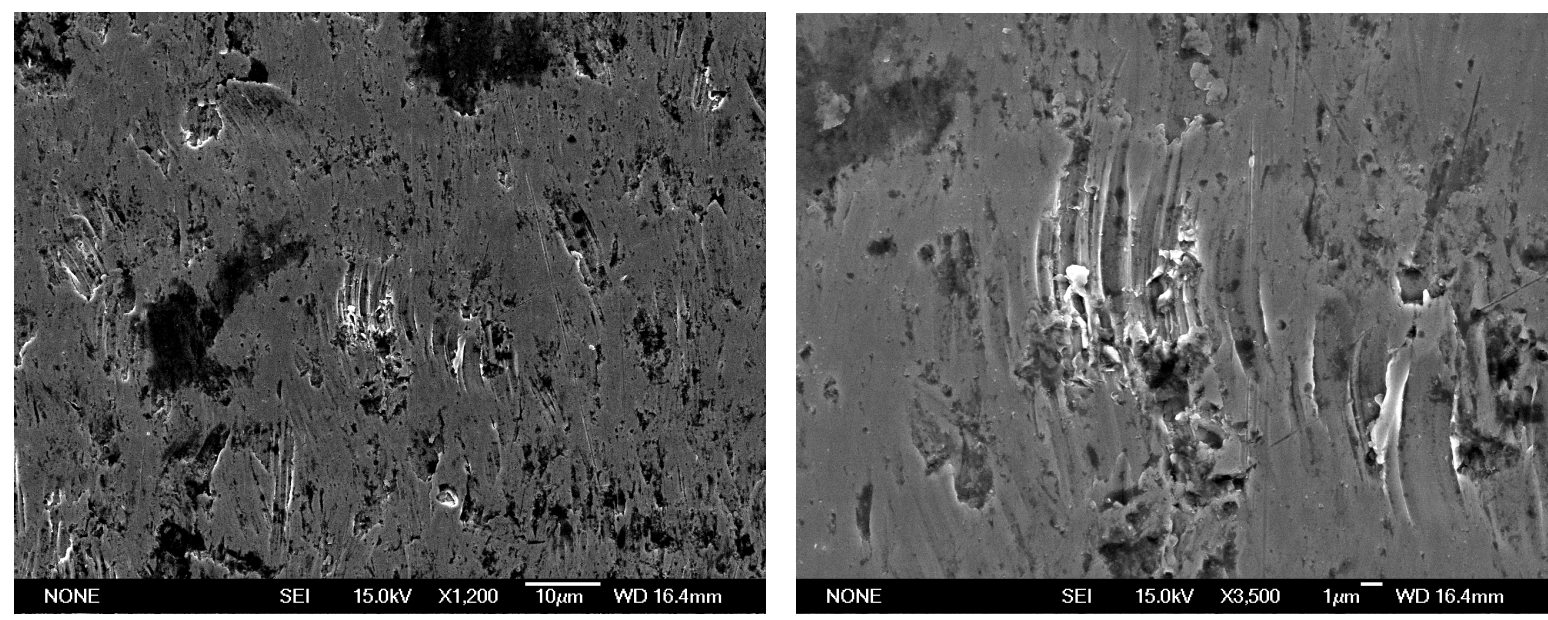

Figure 13: Micrographs showing the surface morphology of bend erosion outer wall. 
(a)

(b)
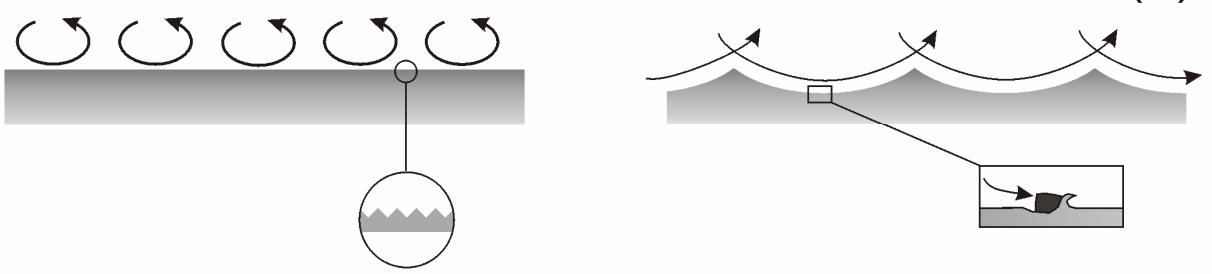

(c)

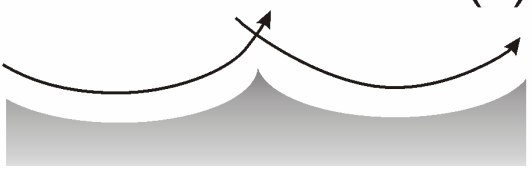

Figure 14: Ripple formation due to turbulence eddies and the influence between micro-roughness and eddy size: (a) initial stage with turbulence boundary layer, micro-roughness determined by prior machining operations; (b) intermediate stage with larger eddies due to changing surface roughness; micro-roughness determined by the individual erosion event; (c) final stage with steady ripple pattern, after [21]. 


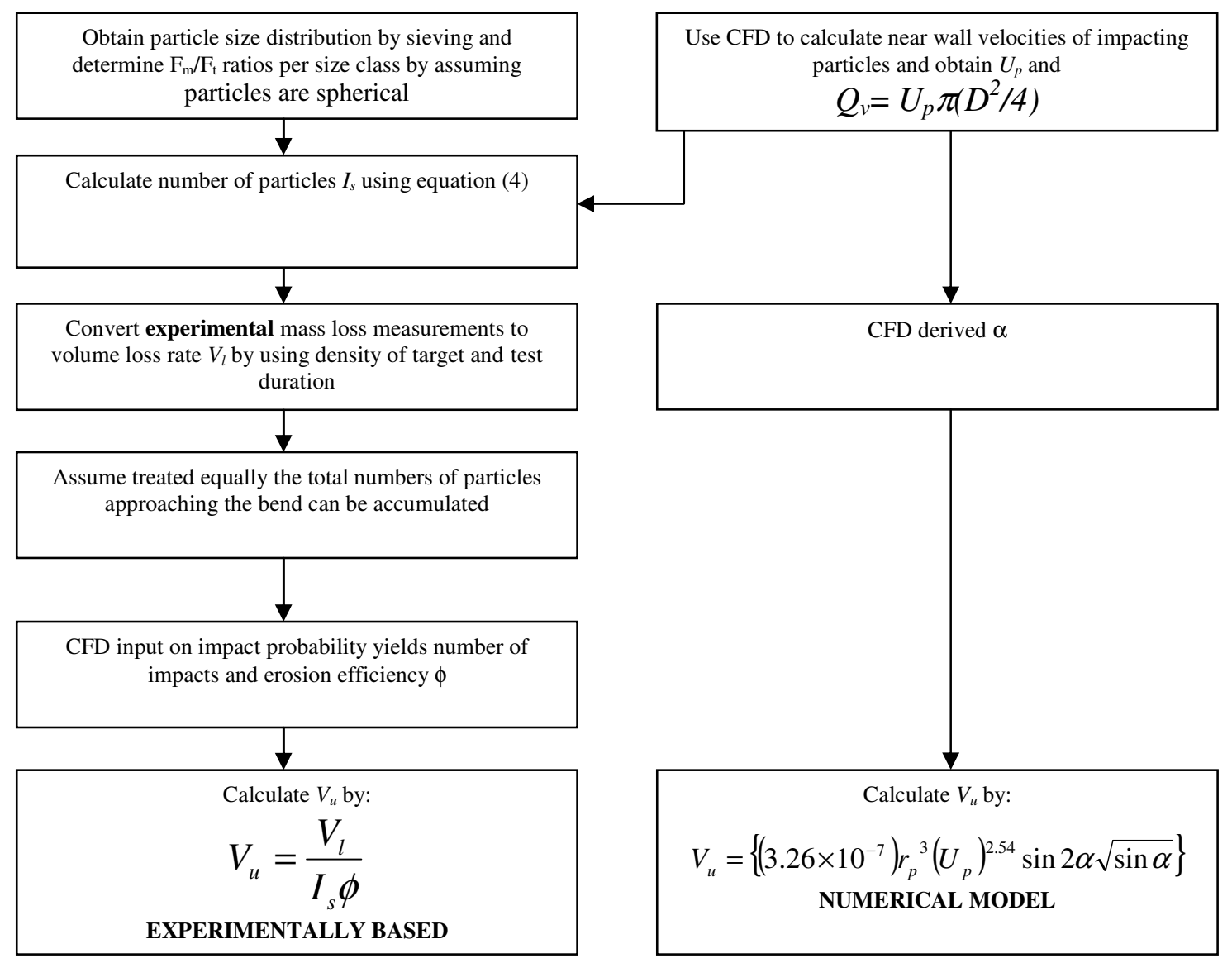

Figure 15: Flow chart of erosion-rate calculations 